\title{
Evaluation of Daytime Sleepiness and Academic Performance in Dentistry Students
}

\author{
Ricardo Augusto Gonçalves Pierri ${ }^{1}$ Marina Reis Oliveira ${ }^{1}$ Guilherme Trento ${ }^{1}$ \\ Rubens Spin-Neto ${ }^{2}$ Marcos Marques Rodrigues ${ }^{3}$ Valfrido Antonio Pereira-Filho ${ }^{1}$
}

${ }^{1}$ Department of Diagnosis and Surgery, Dental School of Araraquara, São Paulo State University, Araraquara, São Paulo, Brazil

2Department of Oral Radiology, Aarhus University, Aarhus, Denmark

${ }^{3}$ Otolaryngology Division, Medical School, University of Araraquara-Uniara, Araraquara, São Paulo, Brazil

\begin{abstract}
Address for correspondence Guilherme dos Santos Trento, DDS, PhD, Department of Diagnosis and Surgery, 1680th Humaitá Street - Dental School of Araraquara, 2nd floor, Araraquara, São Paulo, 14801-903, Brazil (e-mail: guilherme.s.trento@gmail.com).
\end{abstract}

\begin{abstract}
Keywords

- daytime sleepiness

- dentistry

- nasal obstruction

- sleep quality

Objective This study aimed to evaluate the daytime sleepiness and sleep quality of students in different academic years of the dental school program.

Materials and Methods A total of 221 students, from the 1st to the 5th year, answered the questionnaires: Epworth, Pittsburg, Nasal Obstruction Symptom Evaluation, and Berlin, related to daytime sleepiness, sleep quality, nasal obstruction, and obstructive sleep apnea syndrome (OSAS), respectively.

Statistical Analysis The Kolmogorov-Smirnov test was used to assess the normality of continuous quantitative data and, posteriorly, the chi-square test was used to show if there were any associations. The significance level adopted was $5 \%$.

Results An association between daytime sleepiness and nasal obstruction was observed at the beginning of the school year (T1) $(p=0.002)$ and at the end of the school year (T2) $(p=0.043)$. In T2, an association between nasal obstruction and sleep quality was also observed $(p=0.026)$. The academic performance (AP) was only associated with the OSAS in T1 $(p=0.012)$. There was no significant difference in AP between the beginning and the end of the academic year $(p=0.935)$.

Conclusion With the methodology used, it was observed that nasal obstruction influenced sleep quality and daytime sleepiness, and daytime sleepiness did not have any influence on AP.
\end{abstract}

\section{Introduction}

Sleep is a periodic state, commanded by the circadian cycle, when the brain and the body get in a resting state. It is divided into cycles of 90 minutes, and each cycle is subdivided into rapid eye movement (REM) and non-REM sleep. ${ }^{1}$

Many factors can affect sleep, leading to many conditions called sleep disturbances, which are relatively usual in a young adult population. About 20 to $41.7 \%$ of population suffer from lack of sleep, usually motivated by stress, excessive noise, not having a specific time to go to sleep, and/or low sleep time. ${ }^{2}$ The majority of this population is made of university students, who have changes in their routines due to study habits changes when they begin their academic life in universities. ${ }^{3}$
DOI https://doi.org/ $10.1055 / \mathrm{s}-0041-1732772$ ISSN 2320-4753 (c) 2021. European Journal of General Dentistry.

This is an open access article published by Thieme under the terms of the Creative Commons Attribution-NonDerivative-NonCommercial-License, permitting copying and reproduction so long as the original work is given appropriate credit. Contents may not be used for commercial purposes, or adapted, remixed, transformed or built upon. (https://creativecommons.org/licenses/by-nc-nd/4.0/). Thieme Medical and Scientific Publishers Pvt. Ltd. A-12, 2nd Floor, Sector 2, Noida-201301 UP, India 
Nowadays, there are many self-applied questionnaires used to assess daytime sleepiness, sleep quality, and related factors, as obstructive sleep apnea syndrome (OSAS). Of all those questionnaires, we should mention the Epworth Sleepiness Scale, Pittsburgh Sleep Quality Index, Berlin Questionnaire, and Nasal Obstruction Symptom Evaluation (NOSE) questionnaire, all scientifically validated and largely used in researches. ${ }^{4-11}$

The daytime sleepiness must be considered a potential public health issue because it can affect not only the students but also the patients, as some studies identified that daytime sleepiness is associated with accidents at work, car crashes, and even medical errors. ${ }^{12,13}$ Furthermore, there are few researches made to identify the daytime sleepiness prevalence and impacts on health care university students, especially on dental students. ${ }^{14,15}$

Thus, this study aimed to assess, prospectively, daytime sleepiness, sleep quality, and nasal obstruction in dental students and associate the results with the academic performance (AP). To this end, four self-applied questionnaires (Epworth Sleepiness Scale, Pittsburgh Sleep Quality Index, Berlin Questionnaire, and NOSE questionnaire) were used, and the AP data from Araraquara Dental School of São Paulo State University's students were collected in two different times: at the beginning of the school year (T1) and at the end of the school year (T2). This study might show a picture of how daytime sleepiness and sleep quality may affect AP in dental students, and highlight the importance of balancing academic load during graduation years.

\section{Materials and Methods}

\section{Sample Selection}

There were 255 volunteer students selected from the 1 st to the 5 th year of the dental school from a total of 375 students (68\% questionnaire acceptance), to whom the following questionnaires were applied, direct or indirectly regarding sleep quality and quantity: Epworth Sleepiness Scale, Pittsburgh Sleep Quality Index, Berlin Questionnaire, and NOSE questionnaire. Adding to that, the following data were collected: body mass index (BMI), AP, sleep quality complaints, and health problems. The AP was obtained by the graduation school administrative office.

Excluded were the sample students who did not agree to sign the consent form and students who had disorders controlled by continuous use medication that may cause sleepiness.

This study was approved by the Human Research Ethics Committee (CAAE: 58501716.0.0000.5416; number 1.712 . 532/2016).

\section{Questionnaire Application and Data Collect}

The questionnaires were applied in two different times: 2 months after T1 and T2. The AP was assessed at the same two times.

The Epworth Sleepiness Scale is a self-applied questionnaire, which assessed the students' chance to fall sleep in eight situations regarding their daily activities. The global score ranges between 0 and 24, and scores above 10 suggest daytime sleepiness. ${ }^{5}$

The Berlin Questionnaire is made up of 10 questions, divided into three categories. The first category is about snore severity during sleep; the second is about the presence of daytime sleepiness; and the third is about high blood pressure history. Students with positive scores in two or three categories are considered high risk to OSAS. ${ }^{6}$

The Pittsburgh Sleep Quality Index consist of 19 questions about sleep quality, such as night sleep time, sleep latency (time between lying in bed and falling sleep), and sleep disturbances. These questions are divided in seven groups, each group ranging from 0 to 3 , which added to each other to make the Global Score from 0 to 21. Global Scores above 5 indicate bad sleep quality. There are also five other questions in this questionnaire; however, they must be answered by a person who sleeps in the same bed or in the same room with the student. This last five questions regard to clinical information and are not part of the Global Score. ${ }^{4}$

The NOSE questionnaire assesses the presence of nasal obstruction and its severity on students, and it is made up of five questions ranging from 0 to 4 . The score obtained after adding each question score is multiplied by 5 , giving a score between 0 and 100; where scores between 0 and 25 indicate low nasal obstruction level, between 30 and 50 moderate level, and above 55 high nasal obstruction level. ${ }^{7}$

\section{Statistical Analysis}

The software used for statistical analysis were SPSS 21.0 (IBM Corp., United States) and GraphPad Prism 6 (GraphPad Prism Inc., EUA). The Kolmogorov-Smirnov test was used to test the continuous quantitative data normality. The sleepiness questionnaire's data were dichotomized using threshold score above 10 for Epworth Sleepiness Scale, above 5 for Pittsburgh Sleep Quality Index, and two or more categories with positive scores for Berlin Questionnaire. The chi-square test was used to show the possible association between sleepiness and overweight, and between sleepiness and the NOSE questionnaire, at $\mathrm{T} 1$ and $\mathrm{T} 2$. The paired $t$-test was used to verify the possible association between sleepiness and AP, at T1, and if there was difference between $\mathrm{T} 1$ and $\mathrm{T} 2$. The significance level chosen for the statistical analysis was $5 \%$.

\section{Results}

Two hundred and fifty-five students from the 1 st to the 5 th year of a dental school answered four self-applied questionnaires (Epworth, Pittsburgh, Berlin, and NOSE). The AP and weight and height (for BMI calculation) were obtained at two different times: T1 and T2. From the 255 volunteer students, 34 withdrawn or did not inform their AP. The final sample number was 221 students.

Sleepiness data from Epworth, Pittsburgh, and Berlin questionnaires were dichotomized using as thresholds scores above 10 for Epworth, above 5 for Pittsburgh, and two positive categories for Berlin. The absolute and percentage quantity of sleepy students of each school year, according to each questionnaire, are shown in $\boldsymbol{- T a b l e} \mathbf{1}$ at T1 and $\boldsymbol{- T a b l e} \mathbf{2}$ at T2. 
Evaluation of Daytime Sleepiness and Academic Performance in Dentistry Students Pierri et al. 39

Table 1 Absolute and percentage frequency of sleepy students, according to each questionnaire, in each school year in T1

\begin{tabular}{|l|l|l|l|l|l|l|}
\hline Questionnaire & 1st year & 2nd year & 3rd year & 4th year & 5th year & All \\
\hline Epworth & $44(67.7 \%)$ & $27(60.0 \%)$ & $14(48.3 \%)$ & $17(60.7 \%)$ & $27(50.0 \%)$ & $129(58.4 \%)$ \\
\hline Pittsburgh & $46(70.8 \%)$ & $32(711 \%)$ & $21(72.4 \%)$ & $20(71,4 \%)$ & $34(63.0 \%)$ & $153(69.2 \%)$ \\
\hline Berlin & $6(9.2 \%)$ & $0(0.0 \%)$ & $3(10.3 \%)$ & $0(0,0 \%)$ & $0(0.0 \%)$ & $9(4.1 \%)$ \\
\hline $\begin{array}{l}\text { More than two } \\
\text { questionnaires }\end{array}$ & $35(53.8 \%)$ & $22(48.9 \%)$ & $13(44.8 \%)$ & $13(43.4 \%)$ & $17(31.5 \%)$ & $100(45.2 \%)$ \\
\hline All three questionnaires & $2(3.1 \%)$ & $0(0.0 \%)$ & $1(3,4 \%)$ & $0(0.0 \%)$ & $0(0.0 \%)$ & $3(1.4 \%)$ \\
\hline
\end{tabular}

Table 2 Absolute and percentage frequency of sleepy students, according to each questionnaire, in each school year in T2

\begin{tabular}{|l|l|l|l|l|l|l|}
\hline Questionnaire & 1st year & 2nd year & 3rd year & 4th year & 5th year & All \\
\hline Epworth & $53(81.5 \%)$ & $25(55.6 \%)$ & $15(51.7 \%)$ & $14(50.0 \%)$ & $24(44.4 \%)$ & $131(59.3 \%)$ \\
\hline Pittsburgh & $54(83.1 \%)$ & $33(73.3 \%)$ & $21(72.4 \%)$ & $17(60.7 \%)$ & $27(50.0 \%)$ & $152(68.8 \%)$ \\
\hline Berlin & $6(9.2 \%)$ & $0(0 \%)$ & $3(10.3 \%)$ & $0(0 \%)$ & $0(0 \%)$ & $9(4.1 \%)$ \\
\hline $\begin{array}{l}\text { More than two } \\
\text { questionnaires }\end{array}$ & $49(75.4 \%)$ & $19(42.2 \%)$ & $13(44.8 \%)$ & $9(32.1 \%)$ & $14(25.9 \%)$ & $104(47.1 \%)$ \\
\hline All three questionnaires & $3(4.6 \%)$ & $0(0 \%)$ & $2(6.9 \%)$ & $0(0 \%)$ & $0(0 \%)$ & $5(2.3 \%)$ \\
\hline
\end{tabular}

Table 3 Distribution of sleepiness and overweight of evaluated students, according to sleepiness questionnaire, in T1

\begin{tabular}{|l|l|l|l|l|}
\hline Questionnaire & Sleepiness & No overweight & Overweight & $p$-Value \\
\hline \multirow{2}{*}{ Epworth } & No & 90 & 2 & 0.676 \\
\cline { 2 - 5 } & Yes & 125 & 4 & 0.301 \\
\hline \multirow{2}{*}{ Pittsburgh } & No & 65 & 3 & \multirow{2}{*}{$0.001^{\text {a }}$} \\
\cline { 2 - 5 } & Yes & 150 & 3 & \\
\hline \multirow{2}{*}{ Berlin } & No & 209 & 3 & 3 \\
\cline { 2 - 4 } & Yes & 6 & 3 & \\
\hline
\end{tabular}

${ }^{\mathrm{a} p}<<0.05$.

Table 4 Distribution of sleepiness and overweight of evaluated students, according to sleepiness questionnaire, in T2

\begin{tabular}{|l|l|l|l|l|}
\hline Questionnaire & Sleepiness & No overweight & Overweight & $p$-Value \\
\hline \multirow{2}{*}{ Epworth } & No & 88 & 2 & 0.709 \\
\cline { 2 - 5 } & Yes & 127 & 4 & \\
\hline \multirow{2}{*}{ Pittsburgh } & No & 66 & 3 & 0.314 \\
\cline { 2 - 5 } & Yes & 149 & 3 & $0.001^{\text {a }}$ \\
\hline Berlin & No & 209 & 3 & \multirow{2}{*}{0.884} \\
\cline { 2 - 4 } & Yes & 6 & 3 & 3 \\
\end{tabular}

${ }^{\mathrm{a} p}<<0.05$.

The results of the chi-square test of the association between sleepiness and overweight in $\mathrm{T} 1$ are shown in - Table $\mathbf{3}$ and in T2 in - Table 4. - Tables 5 and $\mathbf{6}$ show the results of the association between sleepiness and NOSE questionnaire in $\mathrm{T} 1$ and $\mathrm{T} 2$, respectively.

It was verified an association between overweight and positive scores in the Berlin Questionnaire $(p=0.001)$. This association was maintained in both T1 and T2. When assessed the association between the NOSE questionnaire (assessment of nasal obstruction) and the other questionnaires, a significant association was found between NOSE questionnaire and Epworth questionnaire in T1 $(p=0.002)$ and T2 ( $p=0.043)$. However, the association between NOSE questionnaire and Pittsburgh questionnaire was significant only in T2 $(p=0.026)$. Also in T2, it was observed that the association between NOSE questionnaire and positive values in more than one questionnaire was significant $(p=0.006)$. 
Table 5 Distribution of sleepiness and nasal obstruction (NOSE questionnaire) of evaluated students, according to sleepiness questionnaire, in $\mathrm{T} 1$

\begin{tabular}{|l|l|l|l|l|}
\hline Questionnaire & Sleepiness & No nasal obstruction & Nasal obstruction & $p$-Value \\
\hline \multirow{2}{*}{ Epworth } & No & 66 & 26 & $0.002^{\text {a }}$ \\
\cline { 2 - 5 } & Yes & 66 & 63 & 0.909 \\
\hline \multirow{2}{*}{ Pittsburgh } & No & 41 & 27 & 0.665 \\
\cline { 2 - 5 } & Yes & 91 & 62 & 86 \\
\hline \multirow{2}{*}{ Berlin } & No & 126 & 3 & 0.193 \\
\cline { 2 - 5 } & Yes & 6 & 44 & 45 \\
\hline
\end{tabular}

${ }^{\mathrm{a} p}<0.05$.

Table 6 Distribution of sleepiness and nasal obstruction (NOSE questionnaire) of evaluated students, according to sleepiness questionnaire, in T2

\begin{tabular}{|l|l|l|l|l|}
\hline Questionnaire & Sleepiness & No nasal obstruction & Nasal obstruction & $p$-Value \\
\hline \multirow{2}{*}{ Epworth } & No & 68 & 22 & $0.043^{\text {a }}$ \\
\cline { 2 - 5 } & Yes & 82 & 49 & \multirow{2}{*}{$0.026^{\text {a }}$} \\
\hline \multirow{2}{*}{ Pittsburgh } & No & 54 & 15 & 0.419 \\
\cline { 2 - 5 } & Yes & 96 & 56 & \\
\hline \multirow{2}{*}{ Berlin } & No & 145 & 67 & $0.006^{a}$ \\
\cline { 2 - 5 } & Yes & 5 & 4 & 28 \\
\hline
\end{tabular}

${ }^{\mathrm{a}} \mathrm{p}<0.05$.

Table 7 Mean and standard deviation of sleepiness variables and academic performance of students, according to sleepiness questionnaire, in $\mathrm{T} 1$

\begin{tabular}{|c|c|c|c|}
\hline Questionnaire & Sleepiness & Initial AP & $p$-Value \\
\hline \multirow[t]{2}{*}{ Epworth } & No & $6.8 \pm 0.6$ & \multirow[t]{2}{*}{0.936} \\
\hline & Yes & $6.8 \pm 0.8$ & \\
\hline \multirow[t]{2}{*}{ Pittsburgh } & No & $6.9 \pm 0.7$ & \multirow[t]{2}{*}{0.114} \\
\hline & Yes & $6.8 \pm 0.7$ & \\
\hline \multirow[t]{2}{*}{ Berlin } & No & $6.8 \pm 0.7$ & \multirow[t]{2}{*}{$0.012^{\mathrm{a}}$} \\
\hline & Yes & $6.2 \pm 0.7$ & \\
\hline \multirow[t]{2}{*}{ More than one questionnaire } & No & $6.9 \pm 0.7$ & \multirow[t]{2}{*}{0.203} \\
\hline & Yes & $6.7 \pm 0.8$ & \\
\hline
\end{tabular}

Abbreviation: AP, academic performance.

${ }^{\mathrm{a}} p<0.05$.

The results of paired t-test used to verify the association between sleepiness and AP in T1 and T2 are shown in

- Tables 7 and 8, respectively.

Significant association between AP and sleepiness was observed in the Berlin Questionnaire, which assesses the presence of OSAS, in T1 $(p=0.012)$ but not in T2 $(p=0.614)$. However, there was no difference between the initial and final AP of the evaluated students ( $p=0.935$ ), even considering only the students with positive score in at least one questionnaire $(p=0.927)$.

\section{Discussion}

Insufficient sleep can induce sleepiness and impair learning. This happens because sleepiness leads to reduced attention and memory, and consequently, interferes in AP. ${ }^{16,17}$ Furthermore, there are studies showing that daytime sleepiness reduces operational safety and predisposes to accidents, besides harming the professional's health. ${ }^{12,13,18}$ There are several studies that assess sleep quality and daytime sleepiness in medical school students because this may lead to 
Table 8 Mean and standard deviation of sleepiness variables and academic performance of students, according to sleepiness questionnaire, in $\mathrm{T} 2$

\begin{tabular}{|l|l|l|l|}
\hline Questionnaire & Sleepiness & Final AP & \multirow{2}{*}{0 -Value } \\
\hline \multirow{3}{*}{ Epworth } & No & $6.9 \pm 0.7$ & \multirow{2}{*}{0.120} \\
\cline { 2 - 3 } & Yes & $6.7 \pm 0.8$ & \multirow{2}{*}{0.102} \\
\hline \multirow{3}{*}{ Pittsburgh } & No & $6.9 \pm 0.7$ & \multirow{2}{*}{0.614} \\
\cline { 2 - 3 } & Yes & $6.8 \pm 0.9$ & \\
\hline Morlin & No & $6.8 \pm 0.7$ & 0.059 \\
\cline { 2 - 3 } & Yes & $5.9 \pm 0.9$ & \\
\hline
\end{tabular}

Abbreviation: AP, academic performance.

medical errors. ${ }^{12,13}$ However, studies which seek to identify association between sleepiness or bad sleep quality, usually, collect data in only one period of time, what does not allow to verify if increasing in sleepiness or worsening in sleep quality of students have an association with their AP. Studies with this goal, in health care students, are scarce in literature, ${ }^{19,20}$ and there are hardly any of samples from dental school students. Dentistry is an academic course where students treat patients; and this is why studies about daytime sleepiness in this population are important because this may lead to risks to patient's health in some situations. Therefore, studies, as this one, about assessing associations between daytime sleepiness and bad sleep quality and AP in dental school students, are very relevant.

Different from many authors, ${ }^{3,14,15,21-23}$ sleep quality and AP were assessed in two different times in our study: at the beginning (T1) and at the end of school year (T2). This way, it was possible to lower the bias of a single time assessment, where transitory factors (health problems, psychological problems, etc.) can affect the results. ${ }^{23}$ Bahammam et al, ${ }^{24}$ in their study, used the Epworth questionnaire to evaluate daytime sleepiness in medical school students. As so in our study, they divided students in groups according to each school year. They found that students with "average" AP had higher scores in the Epworth. In our study, higher scores in Epworth were observed in students in the 1st year of dental school, where $67.7 \%$ of these students had daytime sleepiness in $\mathrm{T} 1$ and $81.5 \%$ in $\mathrm{T} 2$. This can be explained, in part, by the fact that students from the 1 st and 2 nd year have almost only lectures and no practical classes, compared with the other years of dental school. In this context, besides daytime sleepiness, there are other factors that can also be associated with AP, as socioeconomic position, life style (smoking, alcohol intake, and overweight), and mental diseases..$^{25}$ This may be true, since we observed an association between overweight and OSAS (Berlin Questionnaire) in both T1 and T2 in our study.

Howell et $\mathrm{al}^{21}$ verified that full-time students with bad sleep quality had lower grades compared with students with good sleep quality, in "Introduction to Psychology" classes. On the other hand, half-time students did not have significant differences in grades between good and bad sleepers. However, when the AP in general was assessed, significant differences were found only when sex and age were added as covariants in the statistical analysis. The author did not found an association between daytime sleepiness and AP. The same results were found by Gray and Watson ${ }^{26}$ who did not find any association between AP and sleep quality. In our study, the evaluation of AP and sleepiness or sleep quality was made in two different times, aiming to verify if variations in AP could be associated to increase of sleepiness or worsening in sleep quality. However, no significant differences were observed in the student's AP between T1 and T2 ( $p=0.935)$.

The Pittsburgh questionnaire is more associated to assessment of sleep quality, while the Epworth questionnaire assesses daytime sleepiness. In our study, these two questionnaires were used together with the Berlin questionnaire, which assesses the presence of symptoms of OSAS, and the NOSE questionnaire (about nasal obstruction). It was observed that the percentage of bad sleepers (69.2\% in T1 and 68.8\% in $\mathrm{T} 2$ ) and sleepy students (58.5\% in $\mathrm{T} 1$ and $59.3 \%$ in $\mathrm{T} 2$ ) was elevated compared with the values found by Alsaggaf et al, ${ }^{23}$ who found 30 and 39\%, respectively. Zailinawati et $\mathrm{al}^{3}$ and Ozder and Eker $^{22}$ also found a lower percentage of daytime sleepiness in students, 28.5 and $35.5 \%$ in their samples, compared with our study. On the other hand, Rodrigues et $\mathrm{al}^{20}$ found a similar percentage of daytime sleepiness (61.62\%) to our study (58.5-59.3\%), and a similar percentage of dental students with bad sleep quality was found by Elagra et $\mathrm{al}^{15}$ (72.5\%). In this last study, the author found a negative association between student's AP and bad sleep quality, and this association was stronger in students with more practical activities. Despite this, it is important to consider that the AP was obtained directly from the students. ${ }^{15}$ In our study, although no significant difference was observed, it must be taken into consideration that this may be due to the fact that AP was obtained directly by the university registrar office, what increases the reliability of data obtained.

Kang and Chen ${ }^{27}$ also evaluated sleep quality and daytime sleepiness in university students in Taiwan by applying the Epworth and Pittsburgh questionnaires. In that study, they also used the Fatigue Severity Scale and observed that irregular bedtime and sleep time mean were associated with only the Pittsburgh questionnaire. Galland et $\mathrm{al}^{28}$ made a meta-analysis that identified a clear association between bad AP and sleep breathing disorders in children and teenagers. In our study, we observed association between students 
with nasal obstruction (NOSE questionnaire) and excessive daytime sleepiness in T1 $(p=0.002)$. In T2, an association between excessive daytime sleepiness and nasal obstruction $(p=0.043)$ and bad sleep quality $(p=0.026)$ was also observed.

Other studies, as one made by Perez-Lloret et al, ${ }^{16}$ also evaluated the association between sleepiness and AP. In that study, the authors evaluated the correlation of sleep duration, daytime sleepiness, attention levels, and AP in teenagers. They observed that the AP correlated with attention decrease, attention decrease correlated with daytime sleepiness, and daytime sleepiness correlated with short sleep time. ${ }^{16}$ In our study, it was observed an association between overweight and nasal obstruction with OSAS in both $\mathrm{T} 1$ and $\mathrm{T} 2$. However, regarding AP, the association found with positive scores in the Berlin questionnaire (for OSAS) occurred only in T1. Veldi et $\mathrm{al}^{29}$ connected daytime sleepiness with sleep quality, workload, and BMI in dental students. The authors found an association between overweight and the increase of daytime sleepiness. This association was not verified in our study ( $p=0.676$ in T1, $p=0.709$ in T2). As well as in our study, Zailinawati et $\mathrm{al}^{3}$ did not find an association between sleepiness and overweight.

Lee et $\mathrm{al}^{17}{ }^{17}$ on the other hand, evaluated 101 teenagers and observed that the insufficient sleep syndrome was associated with many factors, for instance, poor AP and daytime sleepiness. In our study, we observed and association between sleepiness and OSAS (Berlin Questionnaire), but only in T1 (in $\mathrm{T} 2$ there was no significant difference). Alóe et a ${ }^{19}$ observed an increase in sleepiness in 111 medical students of University of São Paulo who answered to the Epworth questionnaire at the beginning and at the end of school year. The authors suggested that fatigue or any other external factor influenced the findings, as there was no decrease in the student's sleeping time. ${ }^{19}$

\section{Conclusion}

In this context, with the methods used, we observed that nasal obstruction had influence in sleep quality and daytime sleepiness. Nevertheless, in our study sample, daytime sleepiness did not influence the AP. This can be explained, in part, by the fact that the AP was obtained directly by the university registrar office in our study, while in other studies that had shown sleepiness influence over AP, it was self-reported. ${ }^{15,17}$

Adding to that, regarding the topic importance, more studies with larger samples must be done to assess daytime sleepiness in dental students, since, until this time, most studies assessed medical students only. ${ }^{12,13,19,20}$

\section{Ethical Approval}

All procedures performed in studies involving human participants were in accordance with the ethical standards of the institutional and/or national research committee and with the 1964 Helsinki Declaration and its later amendments or comparable ethical standards.

\section{Informed Consent}

Informed consent was obtained from all individual participants included in the study.

\section{Funding}

This study was funded by FAPESP (grant number: 2016/00838-2).

\section{Conflict of Interest}

The authors declare that they have no conflicts of interest.

\section{Acknowledgments}

São Paulo Research Foundation(FAPESP), nº 2016/00838-2.

\section{References}

1 Morris CJ, Aeschbach D, Scheer FA. Circadian system, sleep and endocrinology. Mol Cell Endocrinol 2012;349(1):91-104

2 Ohayon MM. Epidemiological overview of sleep disorders in the general population. Sleep Med Res 2011;2(1):1-9

3 Zailinawati AH, Teng CL, Chung YC, Teow TL, Lee PN, Jagmohni KS. Daytime sleepiness and sleep quality among Malaysian medical students. Med J Malaysia 2009; 64(2):108-110

4 Buysse DJ, Reynolds CF III, Monk TH, Berman SR, Kupfer DJ. The Pittsburgh Sleep Quality Index: a new instrument for psychiatric practice and research. Psychiatry Res 1989;28(2):193-213

5 Johns MW. A new method for measuring daytime sleepiness: the Epworth sleepiness scale. Sleep 1991;14(6):540-545

6 Netzer NC, Stoohs RA, Netzer CM, Clark K, Strohl KP. Using the Berlin Questionnaire to identify patients at risk for the sleep apnea syndrome. Ann Intern Med 1999;131(7):485-491

7 Stewart MG, Witsell DL, Smith TL, Weaver EM, Yueh B, Hannley MT. Development and validation of the Nasal Obstruction Symptom Evaluation (NOSE) scale. Otolaryngol Head Neck Surg 2004;130(2):157-163

8 Bertolazi AN, Fagondes SC, Hoff LS, Pedro VD, Menna-Barreto SS, Johns MW. Validação da escala de sonolência de Epworth em português para uso no Brasil. J Bras Pneumol 2009;35(9):877-883

9 Bertolazi AN, Fagondes SC, Hoff LS, et al. Validation of the Brazilian Portuguese version of the Pittsburgh Sleep Quality Index. Sleep Med 2011;12(1):70-75

10 Vaz AP, Drummond M, Caetano-Mota P, Severo M, Almeida J, Winck JC. Tradução do Questionário de Berlim para língua Portuguesa e sua aplicação na identifi cação da SAOS numa consulta de patologia respiratória do sono. Rev Port Pneumol 2011;17(2):59-65

11 Bezerra TF, Padua FG, Pilan RR, Stewart MG, Voegels RL. Cross-cultural adaptation and validation of a quality of life questionnaire: the Nasal Obstruction Symptom Evaluation questionnaire. Rhinology 2011;49(2):227-231

12 Owens JA. Sleep loss and fatigue in medical training. Curr Opin Pulm Med 2001;7(6):411-418

13 Pikovsky O, Oron M, Shiyovich A, Perry ZH, Nesher L. The impact of sleep deprivation on sleepiness, risk factors and professional performance in medical residents. Isr Med Assoc J 2013;15(12):739-744

14 Valic M, Pecotic R, Lusic L, Peros K, Pribudic Z, Dogas Z. The relationship between sleep habits and academic performance in dental students in Croatia. Eur J Dent Educ 2014;18(4):187-194

15 Elagra MI, Rayyan MR, Alnemer OA, et al. Sleep quality among dental students and its association with academic performance. J Int Soc Prev Community Dent 2016;6(4):296-301 
16 Perez-Lloret S, Videla AJ, Richaudeau A, et al. A multi-step pathway connecting short sleep duration to daytime somnolence, reduced attention, and poor academic performance: an exploratory cross-sectional study in teenagers. J Clin Sleep Med 2013;9(5):469-473

17 Lee YJ, Park J, Kim S, Cho SJ, Kim SJ. Academic performance among adolescents with behaviorally induced insufficient sleep syndrome. J Clin Sleep Med 2015;11(1):61-68

18 Merdad RA, Merdad LA, Nassif RA, El-Derwi D, Wali SO. Sleep habits in adolescents of Saudi Arabia; distinct patterns and extreme sleep schedules. Sleep Med 2014;15(11):1370-1378

19 Alóe F, Pedroso A, Tavares SM. Epworth Sleepiness Scale outcome in 616 Brazilian medical students. Arq Neuropsiquiatr 1997;55(2):220-226

20 Rodrigues RN, Viegas CA, Abreu E Silva AA, Tavares P, Tavares P. Daytime sleepiness and academic performance in medical students. Arq Neuropsiquiatr 2002;60(1):6-11

21 Howell AJ, Jahrig JC, Powell RA. Sleep quality, sleep propensity and academic performance. Percept Mot Skills 2004;99(2):525-535

22 Ozder A, Eker HH. The prevalence of excessive daytime sleepiness among academic physicians and its impact on the quality of life and occupational performance. Int J Occup Med Environ Health 2015;28(4):721-730
23 Alsaggaf MA, Wali SO, Merdad RA, Merdad LA. Sleep quantity, quality, and insomnia symptoms of medical students during clinical years. Relationship with stress and academic performance. Saudi Med J 2016;37(2):173-182

24 Bahammam AS, Alaseem AM, Alzakri AA, Almeneessier AS, Sharif MM. The relationship between sleep and wake habits and academic performance in medical students: a cross-sectional study. BMC Med Educ 2012;12:61

25 Sivertsen B, Glozier N, Harvey AG, Hysing M. Academic performance in adolescents with delayed sleep phase. Sleep Med 2015;16(9):1084-1090

26 Gray EK, Watson D. General and specific traits of personality and their relation to sleep and academic performance. J Pers 2002;70(2):177-206

27 Kang JH, Chen SC. Effects of an irregular bedtime schedule on sleep quality, daytime sleepiness, and fatigue among university students in Taiwan. BMC Public Health 2009;9:248

28 Galland B, Spruyt K, Dawes P, McDowall PS, Elder D, Schaughency E. Sleep disordered breathing and academic performance: a Meta-analysis. Pediatrics 2015;136(4):e934-e946

29 Veldi M, Aluoja A, Vasar V. Sleep quality and more common sleep-related problems in medical students. Sleep Med 2005;6(3):269-275 